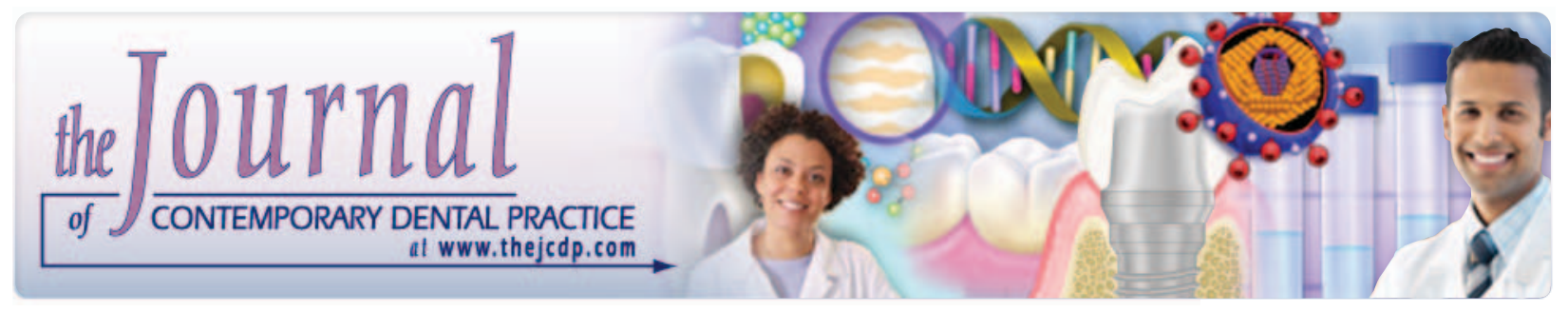

\title{
The Effect of a $16 \%$ Carbamide Peroxide Gel on Mercury and Silver lon Release from Admixed and Spherical Dental Amalgams
}

Shahin Kasraei, DDS, MS; Loghman Rezaei-Soufi, DDS, MS; Mohaddese Azarsina, DDS

\section{Abstract}

Aim: The aim of this study was to investigate the effect of 16 percent carbamide peroxide gel on mercury and silver ions released from admixed and spherical dental amalgams.

Methods and Materials: A total of 96 amalgam discs were prepared from two different types and brands of dental amalgam (admixed and spherical). The samples were stored at room temperature in glass tubes containing distilled water for 24 hours. The specimens were then polished and again immersed in distilled water at room temperature and stored for one month. Samples of both types of dental amalgam were treated with carbamide peroxide 16 percent gel (Nite White, Discus Dental, Inc., Culver City, CA, USA) for 14 and 28 hours (experimental group) and compared to samples not exposed to the bleaching agent but stored continuously in distilled water. Mercury and silver levels of each solution were measured using the VAV-440 analyzer system.

Results: Mercury and silver ions released from the experimental group were significantly greater than from the control group $(p<0.001)$. There was no significant difference between the mean levels of mercury and silver ions in the two kinds of amalgams after treatment with 16 percent carbamide peroxide ( $p=0.119$ for mercury and $p=0.199$ for silver). Increasing the storage time in the carbamide peroxide gel from 14 to 28 hours did not result in significant changes in the amount of ions released ( $p=0.329$ for mercury and $p=0.082$ for silver). Also, the interaction effect between amalgam particles' shape (admixed and spherical) versus storage time (14 versus 28 hours) was not statistically significant ( $p=0.901$ for mercury and $p=0.951$ for silver).

Conclusion: Treatment with 16 percent carbamide peroxide gel increased mercury and silver ions released from admixed and spherical amalgams, compared to samples in the control group, but the difference between the two amalgams was not statistically significant.

Clinical Significance: The amount of mercury and silver ions released from high-copper dental amalgams during bleaching with 16 percent carbamide peroxide is in the safe range of mercury intake for patients.

Keywords: Bleaching agent, carbamide perioxide, dental amalgam, laboratory research, mercury, silver

Citation: Kasraei S, Rezaei-Soufi L, Azarsina, M. The Effect of a $16 \%$ Carbamide Peroxide Gel on Mercury and Silver lon Release from Admixed and Spherical Dental Amalgams. J Contemp Dent Pract [Internet]. 2010 December; 11(6):009-016. Available from: http://www.thejcdp.com/journal/ view/volume11-issue6-rezaeisoufi

\section{Introduction}

Tooth bleaching is rapidly gaining popularity due to patients' desire for whiter teeth and a more attractive smile. ${ }^{1}$ In esthetic dentistry, there are 
two methods of bleaching generally used to treat discolored vital teeth. Bleaching agents for professional use contain high concentrations of carbamide or hydrogen peroxide (30-37 percent) solution, while home bleaching agents contain low peroxide concentrations (3-20 percent). ${ }^{2,3}$

Mouth guard bleaching is usually applied as a home bleaching procedure, with a wide variety of commercial products, frequency, and duration of treatment. Most commercial products consist of carbamide peroxide-based gels, which are usually applied to the external surfaces of the teeth using either a custom or a prefabricated tray. ${ }^{4.5}$

One concern about bleaching materials is their adverse effects on existing restorations in the oral cavity. Several studies have reported that there was little evidence of bleaching agents causing significant changes on dental materials including glass-ionomer cements, ceramics, and gold. However, many in vitro studies have reported a significant increase in mercury release from dental amalgam as a result of treatment with peroxides. $\frac{2.6 .7}{.}$

Amalgam is the most widely used restorative material for posterior teeth because of its physical and mechanical properties, stability, ease of use, and low cost. However, mercury release as a result of contact of amalgam-restored posterior teeth with excessive bleaching material within the mouth guard is of particular concern due to its potential adverse effects on human tissues and the environment. ${ }^{2.8}$

Since the particles' shape and mercury reaction are different in spherical and admixed dental amalgam, so the effect of carbamide peroxide gel on releasing metal ions from these alloys may be different. Some previous studies show these effects. ${ }^{9,10}$ Since there are few studies regarding the differences between admixed and spherical dental amalgams, this study is designed to assess the effect of 16 percent carbamide peroxide gel on mercury and silver ion release from admixed and spherical dental amalgams.

\section{Methods and Materials}

Two commercially available dental amalgams were selected for this in vitro experimental study. The first one was a high-copper admixed amalgam (GS-80; Southern Dental Industries Limited, Bayswater, Victoria, Australia) containing 40 percent Ag, 31.2 percent Sn, and 28.7 percent $\mathrm{Cu}$; and the second was a high-copper, spherical unicompositional amalgam (Oralloy Magicap S; Coltene Co., Cuyahoga Falls, OH, USA) containing 58.3 percent Ag, 28.3 percent Sn, 13.33 percent $\mathrm{Cu}$. The characteristics and chemical compositions of these materials are summarized in Table 1.

Forty-eight specimens of each of the two dental amalgam brands were prepared, for a total of 96 samples. The amalgam capsules were mixed according to the manufacturers' instructions with a dental amalgamator (Doumat 2; Degussa Co., Germany). Each amalgam disc was prepared in a truncated cone shape PVC polymer mold of $9 \mathrm{~mm}$ base and $8 \mathrm{~mm}$ top diameter and $3 \mathrm{~mm}$ height. The external surface area of each amalgam disc was $1.95 \mathrm{~cm}^{2}$.

The specimens were removed from the molds after 60 minutes, placed in sealed glass tubes containing distilled water, and stored for 24 hours at room temperature for completion of the setting of the amalgam. After this 24-hour period the specimens were polished with green and red rubber (DTZ Geozalee 307-14167 Berlin, Germany), followed by a brush and tin-oxide paste at low speed. Once polished, the specimens were then aged in distilled water at room temperature $\left(24^{\circ} \mathrm{C}\right)$ for one month. Following that aging period,

Table 1. Composition of amalgam alloys in percentage by weight and properties.

\begin{tabular}{|c|c|c|c|}
\hline & Manufacturer & Composition & Properties \\
\hline GS-80 & $\begin{array}{l}\text { Southern Dental } \\
\text { Industries Limited. } \\
\text { Bayswater. } \\
\text { Victoria. Australia }\end{array}$ & $\begin{array}{l}40 \% \mathrm{Ag} \\
31.2 \% \mathrm{Sn} \\
28.7 \% \mathrm{Cu}\end{array}$ & $\begin{array}{l}\text { High-copper, admixed amalgam, consisting of } \\
\text { lathe-cut and spherical particles with an alloy to } \\
\text { mercury ratio of } \mathrm{Hg} 47.9 \% \text { iAlloy } 52.1 \%\end{array}$ \\
\hline Oralloy Magicap S & $\begin{array}{l}\text { Coltene Co., } \\
\text { Cuyahoga Falls, } \\
\text { Ohio, USA }\end{array}$ & $\begin{array}{l}58.3 \% \mathrm{Ag} \\
28.3 \% \mathrm{Sn} \\
13.33 \% \mathrm{Cu}\end{array}$ & $\begin{array}{l}\text { High-copper, unicompositional spherical alloy } \\
\text { with an alloy to mercury ratio of } \mathrm{Hg} 46 \% / \text { Alloy } \\
54 \%\end{array}$ \\
\hline
\end{tabular}

The Journal of Contemporary Dental Practice, Volume 11, No. 6, December 1, 2010 
the amalgam discs were removed from the tubes and dried with cotton wool.

Samples in the experimental group (48) were treated with carbamide peroxide 16 percent gel (Nite White; Discus Dental, Inc., Culver City, CA, USA) in tubes containing $3 \mathrm{ml}$ of carbamide peroxide gel and $0.1 \mathrm{ml}$ of distilled water in a manner that the entire amalgam discs' surfaces were coated with the gel. According to the manufacturer's instruction, this gel should be used one to two hours per day, and a twohours-per-day exposure period was selected in this study. The specimens (24 samples in each amalgam group) were kept in these tubes for 14 and 28 hours. The control group samples were immersed in a solution containing $3 \mathrm{ml}$ of $0.1-\mathrm{M}$ phosphate buffer $(\mathrm{pH}=6.5)$ for 14 and 28 hours. After the mentioned periods, the amalgam samples were removed from the assay tubes and rinsed with distilled water to reach a volume of 10 $\mathrm{ml}$ of water in every tube.

Mercury levels of each solution were measured using the VAV-440 mercury analyzer system (Thermo Jarrell Ash Co. SH-22 Model; Franklin, MA, USA). The chemical reaction in this system was based on the cold-vapor atomic absorption method. The solution was treated with nitric acid and sulfuric acid in the presence of potassium permanganate and potassium per sulfate to oxidize all the mercury to mercuric ions $(\mathrm{Hg}++)$. Then the excess oxidant was neutralized with hydroxylamine hydrochloride. Stannous chloride solution reduced the mercury in solution to metallic mercury. The mercury vapor was carried toward the absorption cell by argon gas flow. The mercury vapor absorbed light with the $253.7 \mathrm{~nm}$ wavelength. The mercury concentration in each solution was determined by comparing it with a standard curve of known amounts of mercury.

The silver level was measured the same way as for mercury, but the chemical reaction was based on the flame atomic absorption method. Following the stages of calibration and samples preparation, the silver concentration was determined by comparing the amount of the absorption of samples using the calibration curve in the 328.1 $\mathrm{nm}$ wavelength.

Considering the surface area of each amalgam disc, the amounts of mercury and silver were calculated in $\mu \mathrm{g} / \mathrm{mm}^{2}$. Data were analyzed statistically by using a t-test, two-way ANOVA, and Tukey HSD tests.

\section{Results}

Mean levels of mercury and silver released from Oralloy and GS-80 amalgam after 14 and 28 hours are summarized in Table 2.

The amount of mercury and silver ions released from the experimental group was significantly greater than from the control group $(p<0.001)$, but the two-way ANOVA test results did not show any significant difference between the mean levels of mercury and silver ions in the two kinds of amalgams (admixed and spherical) after treatment with the 16 percent carbamide peroxide bleaching agent ( $p=0.119$ for mercury and $p=0.199$ for silver).

It was indicated from the Tukey HSD tests that increasing the storage time of samples in the 16 percent carbamide peroxide gel from 14 hours to 28 hours also did not result in significant changes

Table 2. Mercury and silver ions released from admixed and spherical amalgams after 14- and 28-hour treatments.

\begin{tabular}{|c|c|c|c|c|c|}
\hline & \multirow{3}{*}{$\begin{array}{c}\text { Time } \\
\text { (hours) }\end{array}$} & \multicolumn{4}{|c|}{ Mean \pm SD levels released in $\mu g_{\_} \mathrm{mm}_{-}$} \\
\hline & & \multicolumn{2}{|c|}{ GS-80 } & \multicolumn{2}{|c|}{ Oralloy Magicap S } \\
\hline & & $\begin{array}{c}\text { Nite White } \\
\text { (16\% carbamide } \\
\text { peroxide) }\end{array}$ & Control & $\begin{array}{c}\text { Nite White } \\
\text { (16\% carbamide } \\
\text { peroxide) }\end{array}$ & Control \\
\hline \multirow{2}{*}{$\mathrm{Hg}$} & 14 & $0.776 \pm 0.230$ & $0.221 \pm 0.028$ & $1.049 \pm 0.507$ & $0.138 \pm 0.070$ \\
\hline & 28 & $0.952 \pm 0.323$ & $0.285 \pm 0.028$ & $1.186 \pm 0.615$ & $0.166 \pm 0.068$ \\
\hline \multirow{2}{*}{$\mathrm{Ag}$} & 14 & $1.452 \pm 0.859$ & $0.013 \pm 0.011$ & $1.029 \pm 0.726$ & $0.020 \pm 0.013$ \\
\hline & 28 & $1.985 \pm 1.000$ & $0.045 \pm 0.023$ & $1.601 \pm 0.858$ & $0.068 \pm 0.013$ \\
\hline
\end{tabular}


in the amount of mercury and silver ions released ( $p=0.329$ for mercury and $p=0.082$ for silver). Furthermore, the interaction effect between amalgam particles' shape versus storage time was not statistically significant $(p=0.901$ for mercury and $p=0.951$ for silver).

\section{Discussion}

The results of the present study indicated that although the amount of ions released after treatment with a 16 percent carbamide peroxide bleaching agent was significantly higher than for the control group, but the difference between the two spherical and admixed amalgam brands was not significant. Some studies have mentioned that aging affects the amount of mercury release from dental amalgam. $\frac{8.11}{}$ Additionally, in most clinical cases patients present with old amalgam restorations at the time of bleaching. Even in the case of new restorations placed when bleaching treatment is planned, some time is needed for bleaching tray fabrication and the actual initiation of the treatment procedure. Any new amalgam restorations are in the wet field of the oral cavity during this waiting period. So, in order to mimic a real-life clinical scenario, all the samples were stored in distilled water for a period of one month.

Body exposure to these metal ions, especially mercury, is a potential hazard and may have adverse health effects. The World Health Organization (WHO) guideline for the maximum intake of mercury is $40 \mu \mathrm{g} /$ day. ${ }^{12}$ In the present study, the average amount of mercury release from each amalgam disc was about $1 \mu \mathrm{g} / \mathrm{mm}^{2}$. The total surface area of each amalgam disc was $195 \mathrm{~mm}^{2}$. Therefore, the average mercury release from a sample over 14- and 28-hour periods was 195 and $390 \mu \mathrm{g}$, respectively. According to the White Nite bleaching instructions, the produce is to be used for two hours per day. As a result, the maximum release of mercury using 16 percent carbamide peroxide in this study was $27.8 \mu \mathrm{g} / \mathrm{day}$, which is below the $40 \mu \mathrm{g} /$ day WHO threshold and in the safe range of mercury intake.

In vitro studies showed that the amount of mercury release depended on both the amalgam brand and the carbamide peroxide concentration..$^{4,13,14}$

Making direct comparisons between the data from this study and published data is difficult, due to limitations in the reporting of the carbamide peroxide concentration or amalgam brands used in previous studies and the lack of standardization of experimental details.

Rotstein et al. ${ }^{13}$ reported that mercury released from amalgams immersed into 10 percent carbamide peroxide solutions after 48 hours was between 23 and $161 \mu \mathrm{g} / \mathrm{ml}$. Al-Salehi et al. ${ }^{7}$ recalculated the data reported by Rotstein et al. ${ }^{13}$ and showed that considering the surface area of the samples, which was $1.9 \mathrm{~cm}^{2}$, the amount of mercury release would be between 0.6 and 4.24 $\mu \mathrm{g} / \mathrm{mm}$, which is consistent with the levels obtained in our study (Table 2). Similarly, the data reported for mercury release by Hummert et $\mathrm{al}^{14}$ and Mackert and Berglund ${ }^{15}$ after recalculation were between 0.014 and $0.020 \mu \mathrm{g} / \mathrm{mm}^{2}$ and $0.016 \mu \mathrm{g} /$ $\mathrm{mm}^{2}$, respectively.

Various studies investigated mercury release from dental amalgam as the result of exposure to bleaching agents, and some of them reported that ion release was increased due to the bleaching agent. ${ }^{6.16 .17}$ Conversely, other studies reported no release of ions from different amalgam brands. ${ }^{15.18}$

In the present study, ion release was expressed in the same way reported by Al-Salehi et al, ${ }^{7}$ i.e., as an amount released per unit surface area of the specimen as a standard form..$^{18}$

Although not statistically significant, the level of mercury release from the spherical alloy (Oralloy Magicap S) was higher than that for the admixed alloy (GS-80), but for silver ion release the outcomes were reversed. These data are similar to the study done by Certosimo et al, ${ }^{9}$ who reported that mercury release from spherical alloy (Tytin; Kerr Corp., Orange, CA, USA) exceeded that of the admix alloy (Valiant, Ivoclar Vivadent, Inc., Liechtenstein). It can be speculated that carbamide peroxide bleaching agent may enhance the release of mercury in different ways from different alloy types of dental amalgam.

Admixed alloys need more mercury for reaction with amalgam due to the larger surface area of the particles, ${ }^{19}$ so it's expected that admixed amalgams would release more mercury than unicompositional spherical alloys. On the other hand, during the setting reaction of unicompositional spherical alloys, more contraction occurs and this contraction causes some microcracks in the amalgam mass. ${ }^{20}$ 
The more microcracks in the mass, the more surface area available for reaction with carbamide peroxide gel, and consequently the more mercury release will occur with spherical amalgam alloys.

Polishing amalgam samples reduces their surface area to react with carbamide peroxide gel, so the amount of ion release decreases $\frac{8.21}{}$ Additionally, scanning electron microscopy and $\mathrm{x}$-ray energy dispersive microanalysis studied by Ferracane et $\mathrm{al}^{19}$ suggested that unpolished amalgam surfaces contain slightly greater surface concentration of gamma1 phase than polished surfaces.

Unicompositional amalgams have more $\varepsilon$ and $\eta$ phases in their final composition ${ }^{20}$ so less corrosion occurs and, as the result, less mercury is released from these amalgams as compared to admixed formulations. In admixed amalgams, a little-gamma2 phase remains around the lathe-cut particles. In addition, admixed amalgams contain a eutectic phase that has more corrosion potential than $\varepsilon$ phase. ${ }^{\underline{20}}$

Considering all these factors, it's expected that the amount of ion release from admixed and unicompositional amalgams would be similar.

It is reported in some studies that ion release is time dependent. $\frac{5,8,22}{}$ Although in the present study mercury and silver release increased from 14 to 28 hours, the increase was not statistically significant. The reason for this outcome could be due to the fact that the diffusion rate of mercury is inversely proportional to the film thickness of the oxide layer covering the amalgam restoration..$^{\frac{23}{}}$ Mercury atoms must migrate through the oxide film to reach the external environment. The surface layer caused by corrosion covers the amalgam samples and inhibits further corrosion in vitro. Intraorally this layer dislodges as the result of occlusion of the teeth and mastication, so ion release may be time dependent in vivo.

The size of amalgam samples used in this study was larger than the average amalgam restoration in patients, but approximately the same size as a class 1 or class 2 amalgam restoration in a molar tooth. Therefore, smaller amalgam restorations would have less mercury release following treatment with 16 percent carbamide peroxide bleaching gel. However, patients may have more than one posterior amalgam restoration in their mouth. In addition, patients who abuse over-thecounter products by prolonged contact periods between the bleaching agent and their amalgam restorations may expose themselves to the risk of increasing their total mercury intake. ${ }^{8}$

In in-vitro studies like the present one, the concentration of the bleaching gel is constant during the period of contact with amalgam samples, but in the mouth, the gel dilutes with time due to saliva secretion, so its effect on amalgam restorations decreases, respectively.

Since there are multiple variables in the mouth such as saliva, the oral cavity $\mathrm{pH}$, and the amount and ways of absorption of the released ions, the relationship between dental amalgam and bleaching agents requires more in vivo studies.

\section{Conclusion}

Within the limits of this study, it was concluded that the difference between the mean surface levels of mercury and silver in the two amalgam brands after treatment with 16 percent carbamide peroxide was not statistically significant, although mercury release was greater in the spherical alloy and silver release was higher in the admixed alloy.

It also was concluded that increasing the storage time of samples in 16 percent carbamide peroxide gel from 14 hours to 28 hours didn't cause significant changes in the amount of ions releaseed.

\section{Clinical Significance}

The amount of mercury and silver ions released from high-copper dental amalgam during bleaching with 16 percent carbamide peroxide is in the safe range of mercury intake for patients.

\section{References}

1. Yeh ST, Su Y, Lu YC, Lee SY. Surface changes and acid dissolution of enamel after carbamide peroxide bleach treatment. Oper Dent. 2005; 30(4):507-15.

2. Gurgan S, Kiremitci A, Yalcin F, Alpaslan $T$, Yazici E. Effect of carbamide peroxide 
treatments on the metal-ion release and microstructure of different dental amalgams. Oper Dent. 2007; 32(5):476-81.

3. Bizhang M, Seemann R, Duve G, Römhild G, Altenburger JM, Jahn KR, Zimmer S. Demineralization effects of 2 bleaching procedures on enamel surfaces with and without post-treatment fluoride application. Oper Dent. 2006; 31(6):705-9.

4. Rotstein I, Dogan H, Avron Y, Shemesh $\mathrm{H}$, Mor C, Steinberg D. Protective effect of Copalite surface coating on mercury release from dental amalgam following treatment with carbamide peroxide. Endod Dent Traumatol. 2000; 16(3):107-10.

5. Robertello FJ, Dishman MV, Sarrett DC, Epperly AC. Effect of home bleaching products on mercury release from an admixed amalgam. Am J Dent. 1999; 12(5):227-30.

6. Rotstein I, Mor C, Arwaz JR. Changes in surface levels of mercury, silver, tin, and copper of dental amalgam treated with carbamide peroxide and hydrogen peroxide in vitro. Oral Surg Oral Med Oral Pathol Oral Radiol Endod. 1997; 83(4):506-9.

7. Al-Salehi SK, Hatton PV, McLeod CW, Cox AG. The effect of hydrogen peroxide concentration on metal ion release from dental amalgam. J Dent. 2007; 35(2):172-6.

8. Rotstein I, Avron Y, Shemesh H, Dogan H, Mor C, Steinberg D. Factors affecting mercury release from dental amalgam exposed to carbamide peroxide bleaching agent. Am J Dent. 2004; 17(5):347-50.

9. Certosimo A, Robertello F, Dishman M, Bogacki R, Wexel M. The effect of bleaching agents on mercury release from spherical dental amalgam. Gen Dent. 2003; 51(4):356-9.

10. Neme AL, Maxson BB, Linger JB, Abbott LJ. An in-vitro investigation of variables influencing mercury vapor release from dental amalgam. Oper Dent. 2002; 27(1):73-80.

11. Brune D. Corrosion of amalgams. Scand J Dent Res. 1981; 89(6):506-14.

12. Jones DW. Exposure or absorption and the crucial question of limits for mercury. J Can Dental Assoc. 1999; 65(1):42-6.

13. Rotstein I, Dogan H, Avron Y, Shemesh H, Steinberg D. Mercury release from dental amalgam after treatment with $10 \%$ carbamide peroxide in vitro. Oral Surg Oral Med Oral Pathol Oral Radiol Endod. 2000; 89(2):216-9.

14. Hummert TW, Osborne JW, Norling BK, Cardenas HL. Mercury in solution following exposure of various amalgams to carbamide peroxides. Am J Dent. 1993; 6(6):305-9.

15. Mackert JR Jr, Burglund A. Mercury exposure from dental amalgam fillings: absorbed dose and the potential for adverse health effects. Crit Rev Oral Biol Med. 1997; 8(4):410-36.

16. Ahn HJ, Song KB, Lee YE, Lee JT, Cho SA, $\mathrm{Kim} \mathrm{KH}$. Surface change of dental amalgam after treatment with $10 \%$ carbamide peroxide. Dent Mater J. 2006; 25(2):303-8.

17. Al-Salehi SK. Effects of bleaching on mercury ion release from dental amalgam. J Dent Res. 2009; 88(3):239-43.

18. Al-Salehi SK, Hatton PV, Miller CA, McLeod C, Joiner A. The effect of carbamide peroxide treatment on metal ion release from dental amalgam. Dent Mater. 2006; 22(10):948-53.

19. Ferracane JL, Mafiana P, Cooper C, Okabe T. Time-dependent dissolution of amalgams into saline solution. J Dent Res. 1987; 66(8):1331-5.

20. Powers JM, Sakaguchi RL. Craig's restorative dental materials. 12th ed. St. Louis: Mosby; 2006. p. 235-67.

21. Canay S, Cehreli MC, Bilgiç S. In vitro evaluation of the effect of a current bleaching agent on the electrochemical corrosion of dental alloys. J Oral Rehabil. 2002; 29(10):1014-9.

22. Berglund A, Pohl L, Olsson S, Bergman M. Determination of the rate of release of intraoral mercury vapor from amalgam. J Dent Res. 1988; 67(9):1235-42.

23. Marek M. The effect of tin in the Ag-Hg phase of dental amalgam on dissolution of mercury. Dent Mater. 1997; 13(6):353-9. 


\section{About the Authors}

Shahin Kasraei, DDS, MS

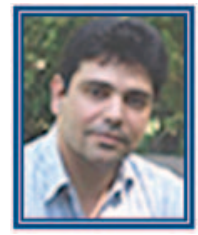

Dr. Kasraei is an associate professor in the Department of Operative Dentistry, Faculty of Dentistry and director of the Dental Research Center of Hamedan Medical Sciences University, Hamedan, Iran. Dr. Kasraei's research interests include laser in dentistry, adhesive systems, and microleakage. Dr. Kasraei is a member of the Iranian Academy of Cosmetic Restorative Dentistry.

e-mail: sh kasraei@yahoo.com

Loghman Rezaei-Soufi, DDS, MS (Corresponding Author)

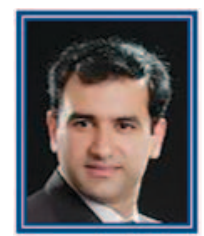

Dr. Rezaei-Soufi is an assistant professor in the Department of Operative Dentistry, Faculty of Dentistry at the Hamedan Medical Sciences University, Hamedan,
Iran. His research interests include laser in dentistry, microleakage, caries research, and epidemiology. Dr. Rezaei-Soufi is a member of the Iranian Academy of Cosmetic Restorative Dentistry.

e-mail: loghmansofi@umsha.ac.ir

Mohaddese Azarsina, DDS

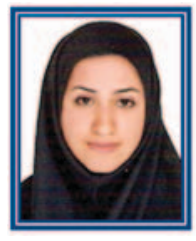

Dr. Azarsina is a post-graduate student of operative dentistry at the Hamedan University of Medical Sciences, Hamedan, Iran. Her research interests are cosmetic dentistry and microleakage.

e-mail: m.azarsina@gmail.com

\section{Acknowledgement}

The authors would like to thank the Dental Research Center and the vice chancellor of research at the Hamedan University of Medical Sciences for supporting this study. 